\title{
System Analysis Applied to Autonomy: Application to Human-Rated Lunar/Mars Landers
}

\author{
Larry A. Young \\ NASA Ames Research Center, Moffett Field, CA, 94035-1000
}

\begin{abstract}
System analysis is an essential technical discipline for the modern design of spacecraft and their associated missions. Specifically, system analysis is a powerful aid in identifying and prioritizing the required technologies needed for mission and/or vehicle development efforts. Maturation of intelligent systems technologies, and their incorporation into spacecraft systems, are dictating the development of new analysis tools, and incorporation of such tools into existing system analysis methodologies, in order to fully capture the trade-offs of autonomy on vehicle and mission success. A "system analysis of autonomy" methodology will be outlined and applied to a set of notional human-rated lunar/Mars lander missions toward answering these questions: 1 . what is the optimum level of vehicle autonomy and intelligence required? and 2 . what are the specific attributes of an autonomous system implementation essential for a given surface lander mission/application in order to maximize mission success? Future human-rated lunar/Mars landers, though nominally under the control of their crew, will, nonetheless, be highly automated systems. These automated systems will range from mission/flight control functions, to vehicle health monitoring and prognostication, to life-support and other "housekeeping" functions. The optimum degree of autonomy afforded to these spacecraft systems/functions has profound implications from an exploration system architecture standpoint.
\end{abstract}

\section{Nomenclature}

$\mathrm{a}_{\mathrm{x}} \quad$ Coefficients, defined in text

$\mathrm{C}_{\mathrm{AS}}$ Autonomous System Complexity

$\mathrm{C}_{\mathrm{EO}}$ Environmental and Operational Complexity

$\mathrm{D}_{\mathrm{I}}$ "Degree of inaccessibility"

$D_{\text {IN }}$ "Degree of interaction" among spacecraft and other intelligent systems to complete a given mission

$\mathrm{D}_{\mathrm{R}}$ "Degree of resistance"

$F_{P} \quad$ Processor speed (instruction or operation)

LOA Level of Autonomy

$\mathrm{m}_{\mathrm{x}} \quad$ Coefficients, defined in text

$\mathrm{m}_{\mathrm{c}} \quad$ Mass of lander "cargo," $\mathrm{kg}$

$\mathrm{m}_{\mathrm{p}} \quad$ Mass of lander mission payload, including crew if any, $\mathrm{kg}$

MROI Mission return on investment

$\mathrm{N}_{\text {crew }}$ Number of crew onboard spacecraft

$\mathrm{N}_{\mathrm{B}} \quad$ Number of robotic behaviors

$\mathrm{N}_{\mathrm{C}} \quad$ Number of control actuators

$\mathrm{N}_{\text {DOF }}$ Number of degrees of freedom, robot mobility
$\mathrm{N}_{\mathrm{L}} \quad$ Lines of software code

$\mathrm{N}_{\mathrm{M}} \quad$ Size of system dynamic memory

$\mathrm{N}_{\mathrm{P}} \quad$ Number of processors

$\mathrm{N}_{\mathrm{R}}$ Number of "robots" (and/or intelligent systems, including automated spacecraft systems)

$\mathrm{N}_{\text {Rule }}$ Number of conditional (heuristic) rules

$\mathrm{N}_{\mathrm{S}} \quad$ Number of sensors

$\mathrm{N}_{\mathrm{V}} \quad$ Number of state space variables

Q QFD-inspired technology-to-goals matrix

$\mathrm{R}_{\mathrm{C}} \quad$ Control input rate

$\mathrm{S} \quad$ Mission success

T Mission duration

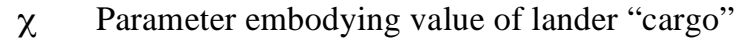
(1 low value to 10 high value)

$\Delta \mathrm{v}$ Total mission "delta-v," $\mathrm{km} / \mathrm{s}$

ı Vehicle intelligence metric

$\varepsilon \quad$ Vehicle autonomous system implementation elegance metric

$\varphi \quad$ Parameter embodying ease of distribution/usage of cargo (1 easy to 10 difficult)

\footnotetext{
${ }^{1}$ Aerospace Engineer, Flight Vehicle Research and Technology Division, Mail Stop 243-12, Associate Fellow.
} 
$\aleph \quad$ Spacecraft system Level of Autonomy (LOA), $0 \leq \boldsymbol{\aleph} \leq 10$, "aleph"

Superscript:

* "Normalized" metrics of vehicle intelligence, elegance, and degrees of inaccessibility, resistance, and interaction, such that range of value of parameters fall within 0 and 10

\section{Introduction}

KEY to NASA's plans for a return to the Moon, and beyond, will be the development of new spacecraft and associated systems. This includes a new generation of human-rated lunar landers and future lander concepts for human exploration of Mars. As is widely known, NASA is currently in the midst of defining and implementing its exploration system architecture, as detailed, in part, in Ref. 1. The development of new human-rated lunar landers is key feature of this architecture; these landers are referred to Ref. 1 as lunar surface access modules (LSAM). Though the general details of the exploration system architecture are fairly advanced in maturity, it still remains to be determined as to the complement of autonomous system technologies that will ultimately be incorporated in this new generation of spacecraft.

System analysis is an essential technical discipline for the modern design of spacecraft and their associated missions. Specifically, system analysis is a powerful aid in identifying and prioritizing the required technologies needed for mission and/or vehicle development efforts. Maturation of autonomous systems, or a.k.a. intelligent systems, technologies, and their incorporation into spacecraft, will dictate the development of new analysis tools, and incorporation of such tools into existing system analysis methodologies, in order to fully capture the tradeoffs of autonomy on spacecraft and mission success. A first-order "system analysis of autonomy" methodology that is tailored for the analysis of crewed spacecraft will be outlined in this paper. This analysis methodology will then be applied to a set of notional human-rated lunar and/or Mars surface lander missions.

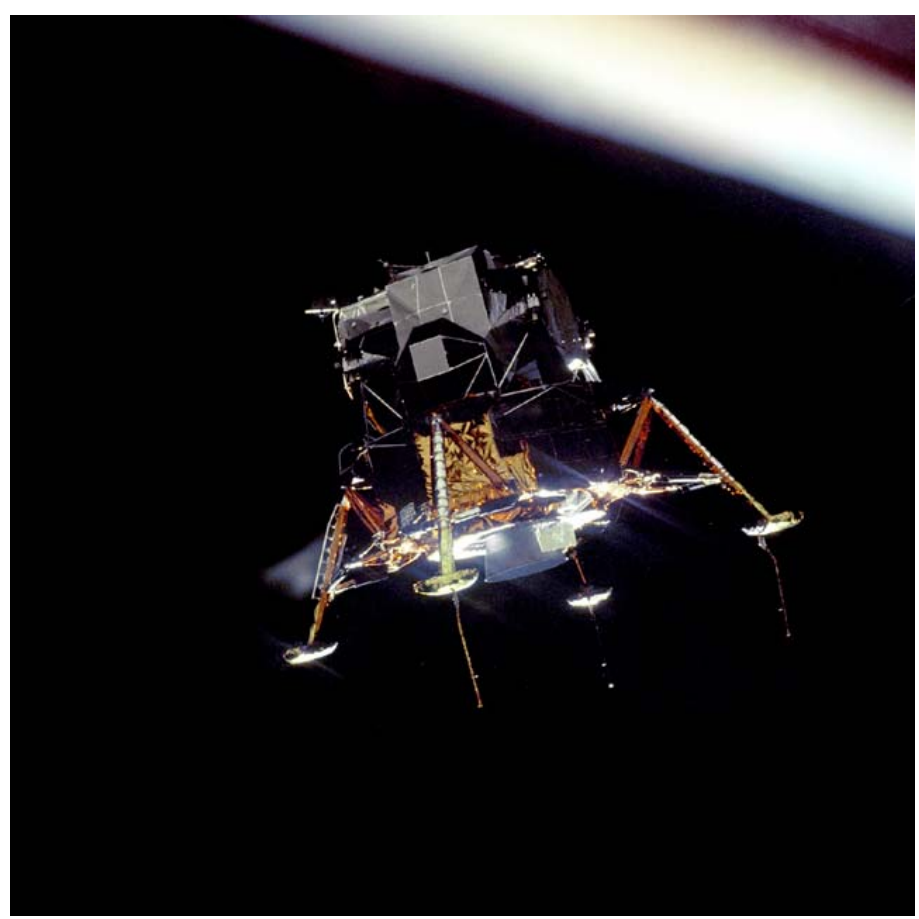

Fig. 1. Apollo 11 Lunar Excursion Module (LEM) "Eagle" in the lunar orbit (NASA Image \# GPN 2000-001210) 
Why not just dust off the old Apollo lunar excursion module (LEM) flight control and avionics drawings and modestly update to current technology (see Fig. 1 and, for example, Ref. 2)? Primarily because, as mission duration increases and explorations go further outward from Earth, planetary surface landers will look less and less like Apollo-type landers and more like one part habitat and one part operations center. Correspondingly, the design and development of future generations of human-rated landers will be as much about the complement and capabilities of the surface operation and scientific equipment carried by the lander as it will be about the lander itself.

For human-rated lunar/planetary surface landers, high levels of vehicle autonomy could be a powerful enabling force as to mission capability. Other than the most qualitative of assessments, how can cost/benefit analysis for incorporation of autonomous system technologies into crewed spacecraft be performed? The first step needs to be the definition of metrics for autonomy that are unambiguous and quantifiable. Fundamental concepts such as autonomy, intelligence, and elegance for planetary aerial vehicles (a.k.a. aerial explorers) and high altitude long endurance (HALE) uninhabited aerial vehicles (UAV) was initially presented in Refs. 3-4. Metrics associated with these properties for autonomous aerial vehicles were employed to develop a system analysis framework for assessing technology portfolios for such platforms. This system analysis work was further expanded upon in Refs. 5-6. It will be demonstrated in this paper that the technology portfolio and associated system analysis methodologies detailed in Refs. 3-6 can be extended to crewed and robotic spacecraft and associated systems. In particular, this paper will investigate the autonomous system technology portfolio issues related to human-rated surface landers. Because of its more expansive nature, as compared to the metrics/scales used in Ref. 4 and Ref. 6, the level of autonomy metric scale defined in Ref. 3 will be used in this paper. These metrics will support the analysis of automation and autonomous system technology investments to support development and use of humanrated lunar and planetary surface landers. This paper is a work in progress, but hopefully presents initial results of general interest.

Once having defined quantifiable autonomy metrics for spacecraft, reasonable first-order functional relationships are defined relating vehicle and mission characteristics to aforesaid autonomy metrics, and ultimately related to individual autonomous system technologies. By way of illustration, Fig. 2a-b shows notional drawings of two different types of surface landers potentially used for said notional missions. Figure 2a is a notional drawing of a crewed lunar lander; Fig. $2 b$ is illustrates a "pallet"-version of an automated cargo lander. The two notional surface landers also represent a spectrum of mission capabilities, vehicle design, and technology challenges.

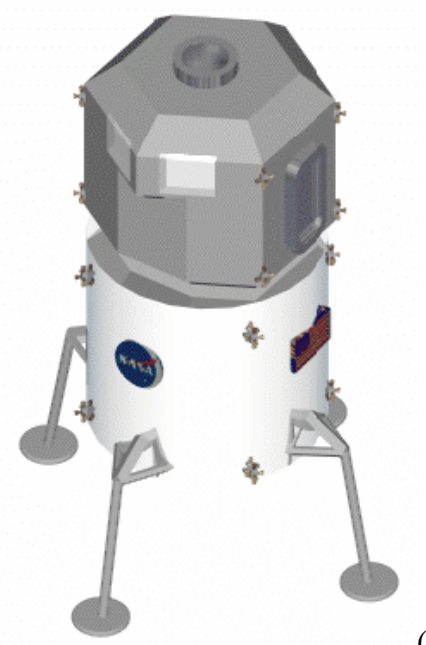

(a)

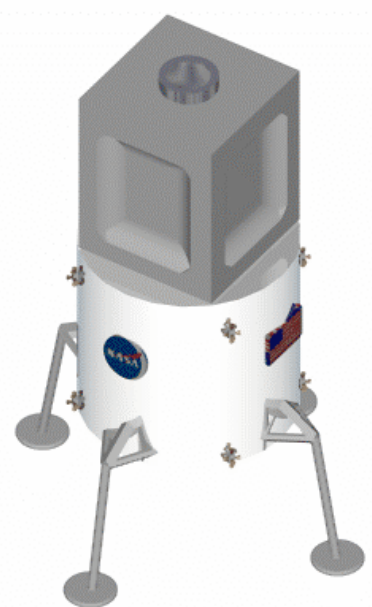

(b)

Fig. 2. (a) Notional Crewed Surface Lander and (b) Automated Cargo Lander Variant

It is also important to note that the greatest impact of autonomous system technology is not limited to its implementation on a single spacecraft platform/system, or even multiple variants of a single vehicle type, but rather the greatest impact will result from the application of autonomy to heterogeneous spacecraft systems working in cooperation/collaboration with each other to achieve mission success. Figures 3a and 3b show two examples of cooperating autonomous space systems: (1) autonomous "test driving" of exploration equipment and (2) 
establishment of long-term (unattended) robotic outposts that provide a capacity for "virtual presence" by Earth-side researchers and perhaps even the general public.
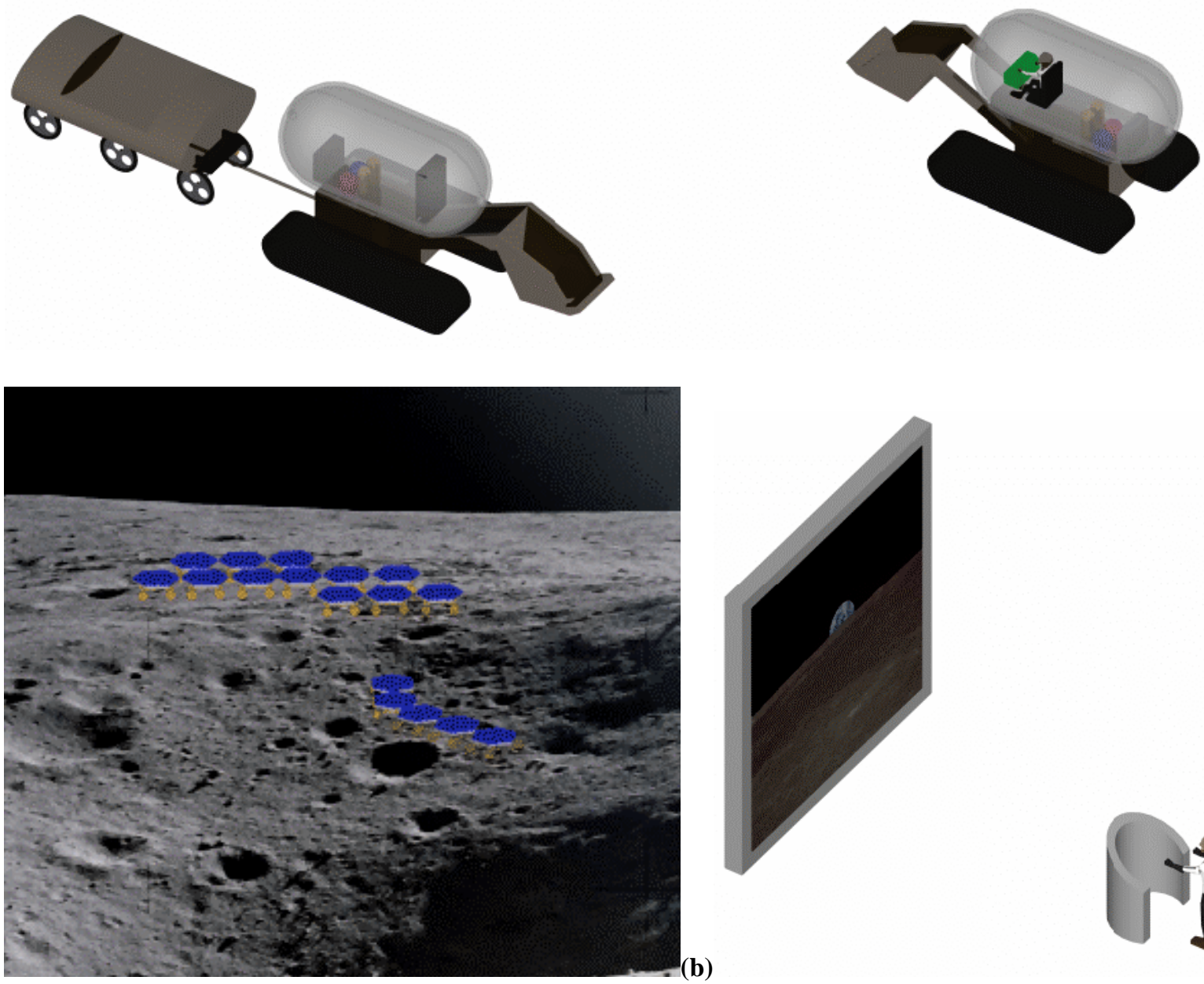

Fig. 3a-b. Examples of Collaborative Operations: (a) Test Drive of Exploration Equipment and (b) LongTerm Robotic Outposts and (c) Virtual Presence

\section{Future Missions and Required Spacecraft Autonomy and Intelligence}

\section{A. Autonomy}

Numerous researchers have attempted to define autonomy in terms of a Level of Autonomy (LOA) metric and scale. Most such work has focused on either terrestrial vehicles and systems - see, for example, Refs. 4, 7, 8, and 9 - or, alternatively, on purely robotic spacecraft or systems, e.g. Ref. 3. A few attempts have been made to consider autonomy and autonomous system technologies in the context of human-rated spacecraft, notably Refs. 10-12. In most cases the proposed LOA metric/scale becomes quite complicated and oftentimes fails to deal with the type of issues that need to be addressed by vehicle or mission system analyses. Table 1 defines the LOA used in this paper; it is based, in large part, on the work of Ref. 3. As will, hopefully, be seen at the conclusion of this paper, this level of autonomy scale provides the proper balance between simplicity and flexibility to address the types of vehicle and mission design issues studied in spacecraft system analysis. Further, this space-system oriented LOA can be mapped to a simpler, comparable LOA developed for terrestrial high-altitude and long endurance (HALE) uninhabited aerial vehicles (UAV), Ref. 4. The level of autonomy scale summarized in Table 1 is quite expansive 
in nature. It defines autonomous system characteristics from fairly simple devices/systems that are manifested in multitude current spacecraft systems to highly speculative capabilities that perhaps are decades away from being realized.

Table 1. Proposed Spacecraft and Planetary Surface Operation Systems Autonomy Levels

\begin{tabular}{|c|c|c|}
\hline $\begin{array}{c}\text { Level } \\
\#\end{array}$ & Level Description & Capability \\
\hline 10 & Legacy/Legate & $\begin{array}{l}\text { Human-surrogate capability to conduct long-term (perhaps years or decades) high-level exploration and } \\
\text { scientific investigation. }\end{array}$ \\
\hline 9 & $\begin{array}{l}\text { Human Explorer } \\
\text { Assistant }\end{array}$ & $\begin{array}{l}\text { Limited human-level surrogate capability that works in close conjunction with human explorers and } \\
\text { oftentimes acts as a liaison or intermediary for humans with other robotic systems }\end{array}$ \\
\hline 8 & $\begin{array}{l}\text { Integrated, Optimal } \\
\text { Autonomy \& Design }\end{array}$ & $\begin{array}{l}\text { Autonomy considerations are implemented intrinsically in spacecraft design and mission simulation. } \\
\text { Additionally, for vehicles with "morphing," hybrid, or adaptive capability, autonomous system } \\
\text { characteristics are modified in accordance with revised vehicle characteristics (i.e. a simultaneous } \\
\text { autonomous system and physical transmogrification). }\end{array}$ \\
\hline 7 & $\begin{array}{l}\text { Robotic Ecosystem - } \\
\text { Participant }\end{array}$ & $\begin{array}{l}\text { Systems are part of a large and robust robotic ecosystem. All robotic systems part of this ecosystem } \\
\text { must collaborate, and sometimes compete, for resources and other (oftentimes provided by human } \\
\text { explorer) rewards. Such an ecosystem is only likely during and in support of human exploration } \\
\text { campaigns. Missions being supported by such robotic ecosystems tend to be open-ended in terms of } \\
\text { scope and duration. }\end{array}$ \\
\hline 6 & $\begin{array}{l}\text { Robotic Symbiosis - } \\
\text { Leader/Co-Equal }\end{array}$ & $\begin{array}{l}\text { Automation for extended missions (i.e. multiple sorties with multiple automated cycles of } \\
\text { servicing/recharging/refueling) is applied across multiple heterogeneous robotic systems, where the } \\
\text { spacecraft, or planetary surface operation systems, take on leadership and or co-equal roles with other } \\
\text { systems (necessitating robust "negotiation" for information and energy resources). }\end{array}$ \\
\hline 5 & $\begin{array}{l}\text { Robotic Symbiosis - } \\
\text { Subordinate or } \\
\text { Dependent }\end{array}$ & $\begin{array}{l}\text { Automation for the mission is applied across multiple heterogeneous robotic systems, in addition to the } \\
\text { spacecraft, for the whole of the mission. Spacecraft, or planetary surface operation system, is primarily } \\
\text { subordinate to some other robotic system, which provides guidance and support. }\end{array}$ \\
\hline 4 & $\begin{array}{l}\text { Opportunistic Self- } \\
\text { Modifiable Goals and } \\
\text { Lines of Investigation }\end{array}$ & $\begin{array}{l}\text { Mission goals/objectives and approaches can be completely (autonomously) redefined as a consequence } \\
\text { of information garnished during the course of the mission (i.e. things discovered and hypotheses } \\
\text { disproved or revised). Sophisticated, intelligent sensors are employed on the spacecraft or robotic } \\
\text { system. }\end{array}$ \\
\hline 3 & $\begin{array}{l}\text { Search, Inquiry, and } \\
\text { Decisions through } \\
\text { "Discovery" }\end{array}$ & $\begin{array}{l}\text { Spacecraft, or robotic planetary surface operations system, implements behaviors, rather than } \\
\text { flight/mission scripts. Heuristic and/or stochastic search and find methodology employed to find key } \\
\text { science-driven features of interest. }{ }^{\dagger} \text { Adaptive fault/anomaly logic implemented. }\end{array}$ \\
\hline 2 & $\begin{array}{l}\text { Changeable (though still } \\
\text { scripted) Mission }\end{array}$ & $\begin{array}{l}\text { Ability to enable scripted contingency plans based upon pre-defined (well-posed) conditional logic } \\
\text { conditions." }\end{array}$ \\
\hline 1 & $\begin{array}{l}\text { Execute Pre-Planned } \\
\text { Missions }\end{array}$ & $\begin{array}{l}\text { Can execute a scripted mission plan without human intervention; only limited contingency/fault } \\
\text { capability. }\end{array}$ \\
\hline
\end{tabular}

Notes:

*Navigation limited to simple sensors and Inertial Measurement Units (IMUs).

${ }^{\dagger}$ Navigation based on sophisticated (non-GPS) sensors, including sun- or star-trackers, LIDAR, RADAR, etc.

${ }^{\S}$ Navigation suite must include vision-based systems. 


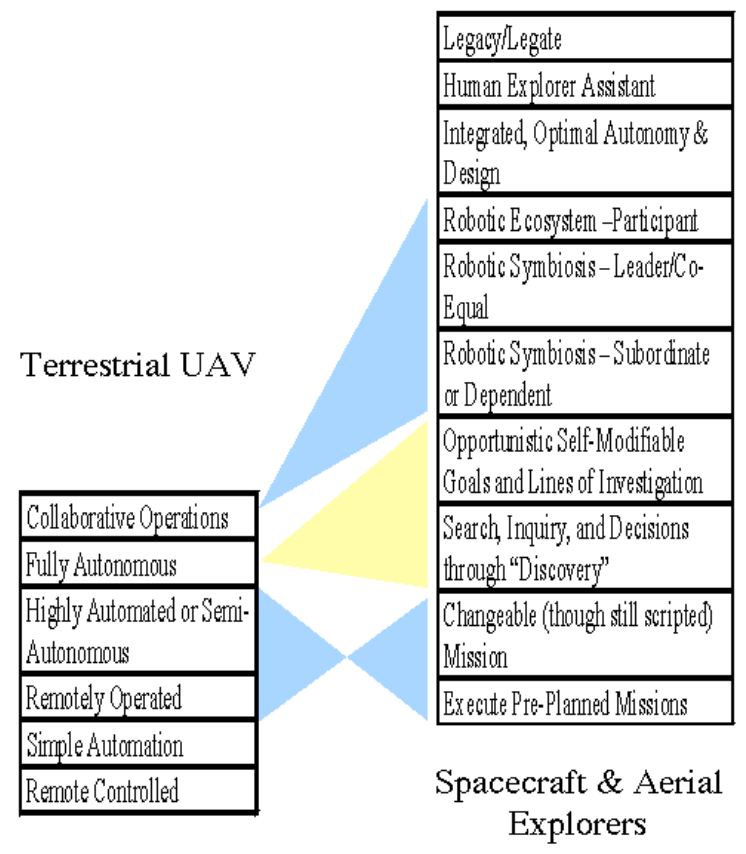

Fig. 4. Mapping of Ref. 1 UAV LOA against Spacecraft \& Robotic Explorer Autonomy Metrics

There is a general presumption that spacecraft autonomous system technologies will be essential to perform routine functions - e.g. automated cargo landers developed to support supply chain logistics for future lunar and planetary surface explorations. Further, though, it will be argued, and supportive analysis provided, that even crewed surface landers will require high-levels of system autonomy (autonomy in the context of being performed by machine and not human, whether on the ground or onboard the spacecraft) in order to achieve acceptable levels of mission success while minimizing cost and risk. It is still arguable for relatively short duration, and lower Earth orbit (LEO) or cis-lunar, missions whether building in high-levels of autonomy and vehicle intelligence is cost effective with acceptable risk for crewed spacecraft - refer, for example, to Ref. 12. But, on the other hand, as missions become longer in duration, as semi-permanent bases/encampments are established, and as mankind travels deeper into space, then autonomy (and the associated concept of intelligence) will surely be necessary for both crewed and crewless spacecraft and surface operation systems. Though it is far from a settled issue it would seem, though, that the new exploration architecture would incorporate a fairly sophisticated level of vehicle autonomy into the next generation of crewed spacecraft.

\section{B. Various Notional Lander Missions and Overall Characteristics}

In order to fully appreciate the challenges of defining the scope of the system analysis problem it is first necessary to distinguish between exploration activities in support of infrastructure development, expeditionary campaigns, missions, and investigations. Arguably investigations and, to a lesser degree, missions can be considered to be science-driven because we are exploring the unknown. On the other hand, infrastructure development, expeditionary campaigns, and some missions are exploration-driven.

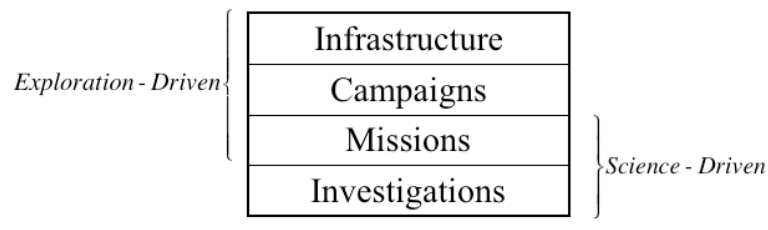

Fig. 5. A Notional Hierarchy of Exploration Activity 
Examples of expeditionary campaigns and missions involving surface landers are shown in Table 2 . These representative missions will be referred to in later sections of the paper - particularly in the context of benchmarking spacecraft autonomy metrics and establishing functional relationships for the proposed "system analysis for autonomy" methodology.

\section{Table 2. Representative (Notional Lunar) Lander Missions}

Short Stay Excursions Mission/flight profile: Transit to and land on lunar surface; mission duration on the order ten to sixteen days; perform short duration focused science investigations and/or high priority infrastructure staging activity, in the immediate area of the lander, during stay. Critical capability: system reliability and overall safety. Technical challenges: Performance versus weight trades. Autonomous system technology challenges: Improved pilot/crew situational awareness (e.g. synthetic vision) during descent phase as well as improved overall system reliability by means of more robust fault-tolerant control systems and computers onboard the vehicle. Risk/hazard: failure of critical flight systems during descent/ascent.

Extended Stay Mission/flight profile: Conduct surface operations from a lander for a minimum of forty days for lunar missions (maybe as long as a year or more for some Mars mission scenarios); surface operations would include not only science investigations but infrastructure development efforts such as lunar base/encampment assembly/construction as well as technology demonstrations such a robotic system trials and "test driving" advanced spacecraft systems for future exploration efforts; surface lander must serve both a space-limited but robust habitat for extended occupancy as well as providing functionality for conducting remote and semiautonomous surface operations and science campaigns. Critical capability: To perform surface operations (in terms of duration, the number of crew on the surface, and the types of tasks performed) well beyond the experience with Apollo. Technical challenges: safe and robust environmental control and overall cabin habitability while maximizing efficiency of surface operations. Autonomous system technology challenges: highly reliable fault-tolerant "networks" of critical spacecraft systems; surface operation teleoperation/telepresence and semi-autonomous control consoles; science stations control and analysis systems; "smart" furnishing to maximize utility of limited cabin space; robotic smart field assistants to offload crew for surface operations. The high level of crew involvement in system maintenance/oversight typified by ISS experience would be unacceptable in the context of a lunar or Mars mission. Risk/hazard: failure of critical systems during extended stay excursions.

Automated Cargo Deployment (Pallet-Version) Mission/flight profile: Infrastructure development efforts as well as extended stays enabled by lunar habitats will dictate a robust method for re-supply to the lunar and/or planetary surfaces. Critical capability: maximum payload capacity and flexibility in loading and unloading and stowage. Technical challenges: to maximize commonality with the crewed surface landers (and other types of automated cargo landers) to minimize costs while at the same time yielding maximum cargo-carrying capacity. Autonomous system technology challenges: reliable spacecraft automation particularly for the landing phase of the descent; this will require hazard avoidance at challenging landing sites but also high degree of precision and flight safeguards for landing near high-value, pre-existing surface assets and personnel (such as habitats, lunar observatories, etc.). Risk/hazard: loss of vehicle and possibly surface assets upon landing.

Automated Cargo Deployment (Combined Container/Habitat-Module-Version) Mission/flight profile: Periodic transit to and deployment of habitat modules and other such facilities to enable lunar bases and extended-stay encampments at key sites. Critical capability: Safely cradle high-value and likely irreplaceable assets to lunar/planetary surface. To provide for a more sophisticated automated surface lander uniquely tailored for the conveyance and deployment (on the ground) of habitat and surface operation infrastructure assets. Technical challenges: flexible/adaptable mechanical, electrical, and control interfaces to handle disparate largescale items of "cargo" with respect to the lander descent module. Autonomous system technology challenges: automated/robotic "cargo-handling" deployment systems of the habitat to the ground. Risk/hazard: damage to habitat assets during landing or deployment from cargo lander to surface site for ultimate emplacement.

Automated Cargo Deployment (ISRU/Utilities Version) Mission/flight profile: the transport of more specialized payloads than more general kinds of "cargo." Critical capability: A highly specialized surface lander custom modified, or designed, to land one-of-a-kind, large-scale technology demonstrations (such as In-Situ Resource Utilization (ISRU) "refineries") or "public utility" systems (such as a nuclear power sources, "greenhouses," or bio-quarantine facilities (for returning astrobiology samples from Mars or the outer planets)). Technical challenges: each specialized payload while have its own unique engineering challenges; the cargo lander, though, should have sufficient generality/flexibility in its interfacing with the payload that significant 
reworking of such interfaces would not have to take place for each new payload. Autonomous system technology challenges: "plug and play" architecture concepts. Risk/hazard: improper or poorly tested interfaces between the lander and the payload.

"Double Eagle" Surface Lander Deployment Mission/flight profile: optimized design to maximize the amount and distribution/deployment of cargo to the lunar surface; transit to lunar orbit two "pallet"-version automated lunar cargo landers via a single service module, or transit vehicle; deploy the two cargo landers to two different sites on the lunar surface; provides ability to pre-stage supply caches on the lunar surface prior to a major expeditionary campaign as a long-distance surface trek via crewed lunar rovers. Critical capability: Provide an efficient means of pre-staging expeditionary assets/resources across lunar surface. Technical challenges: Specialized interface hardware (and likely transit vehicle modifications) and docking maneuvers to enable the automated transport/transit and deployment of multiple surface landers during a single flight. Autonomous system technology challenges: cargo landers have to be fully automated with high system redundancy and reliability; descent/landing hazard avoidance technologies are critical. Risk/hazard: fully automated mission, even during the transit phase.

Orbital Facility Build-Up Mission/flight profile: upon conclusion of surface excursions the crewed ascent modules not only rendezvous with, dock, and transfer crew to CEV command modules but are reused (not jettisoned and expended) as a component of a nascent orbital facility; the orbital lunar (and possibly Mars) facility would be composed of a combination of recycled ascent modules and dedicated system components launched from Earth to complete the facility. Critical capability: recycling otherwise "expended" spacecraft assets might enable the construction of lunar and Mars orbital facilities that might not be feasible by any other means; such recycling ideas have been previously proposed with respect to shuttle external tanks and retired shuttles for augmenting the LEO infrastructure. Technical challenges: uncertainty in the feasibility and magnitude of effort in order to perform such in-space "recycling." Autonomous system technology challenges: enabling autonomous system flexibility to allow reprogramming for systems to radically different uses than originally intended (e.g. "plug and play" computer/software architectures). Need to be designed to be reused. Risk/hazard: in-space/onsurface longevity of spacecraft elements, particularly the recycled ascent modules, and re-supply of spent fuel for attitude control; viability of transforming/modifying the interior of an ascent module (while in space) into a longterm habitable work/living area in an orbital environment.

Table 3 illustrates the interdependence and criticality of individual surface lander missions with respect to the larger-in-scope notional expeditionary campaigns and infrastructure development activity noted in the Fig. 5 hierarchy of exploration activity. Note that the (six) individual missions/mission capabilities can be qualitatively rated in terms of criticality (the value of zero being assigned for negligible contribution and ten for essential) to the corresponding notional expeditionary campaigns or infrastructure efforts. Such assessments are the purview of high-level mission planners and the assignment of values provided below is for illustration purposes only.

Table 3 - Exploration Campaigns building upon individual Missions and Capabilities: Interdependence and Criticality

\begin{tabular}{|l|c|c|c|c|c|c|}
\hline $\begin{array}{l}\text { Campaigns } \\
\text { Or Infrastructure }\end{array}$ & $\begin{array}{c}\text { Short Stay } \\
\text { Excursions }\end{array}$ & $\begin{array}{c}\text { Extended } \\
\text { Stay }\end{array}$ & $\begin{array}{c}\text { Automated } \\
\text { Cargo } \\
\text { Deployment } \\
\text { (Pallet) }\end{array}$ & $\begin{array}{c}\text { Automated } \\
\text { Cargo } \\
\text { Deployment } \\
\text { (Habitat) }\end{array}$ & $\begin{array}{c}\text { Automated } \\
\text { Cargo } \\
\text { Deployment } \\
\text { (ISRU/Utilities) }\end{array}$ & $\begin{array}{c}\text { 'Double } \\
\text { Eagle” } \\
\text { Deployment }\end{array}$ \\
\hline $\begin{array}{l}\text { Human Bases \& } \\
\text { Encampments }\end{array}$ & 4 & 10 & 8 & 8 & 8 & 0 \\
\hline Expeditionary Surface Treks & 6 & 8 & 10 & 0 & 8 & 0 \\
\hline $\begin{array}{l}\text { Test Drive (for evaluation of } \\
\text { future exploration systems) }\end{array}$ & 6 & 8 & 10 & 6 & 0 & 0 \\
\hline $\begin{array}{l}\text { Lunar Observatories } \\
\text { In-Situ Resource } \\
\text { Demonstrations }\end{array}$ & 0 & 7 & 7 & 0 & 10 & 0 \\
\hline $\begin{array}{l}\text { Robotic Outposts \& Virtual } \\
\text { Presence }\end{array}$ & 8 & 5 & 8 & 0 & 3 & 0 \\
\hline $\begin{array}{l}\text { Lunar/Planetary Orbital } \\
\text { Facilities }\end{array}$ & 10 & 10 & 0 & 0 & & 0 \\
\hline
\end{tabular}


Figure 6a-b provides for illustration some simple "mission profiles" for a few of the Tables 2-3 notional expeditionary campaigns. The necessity to sometimes combine a series of missions together to support a single exploration campaign can be seen from these simple examples.

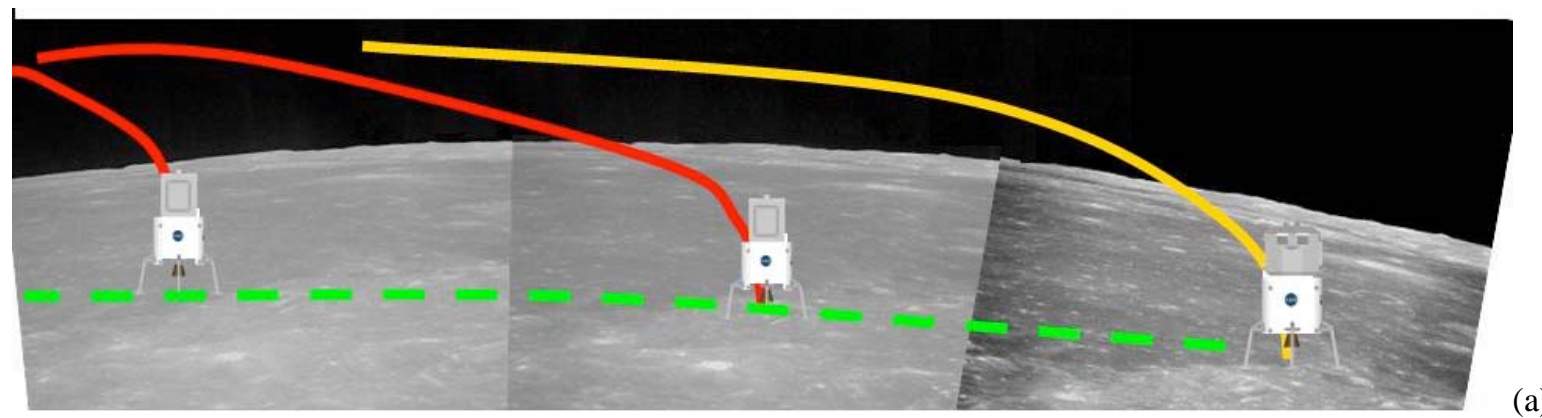

(a)

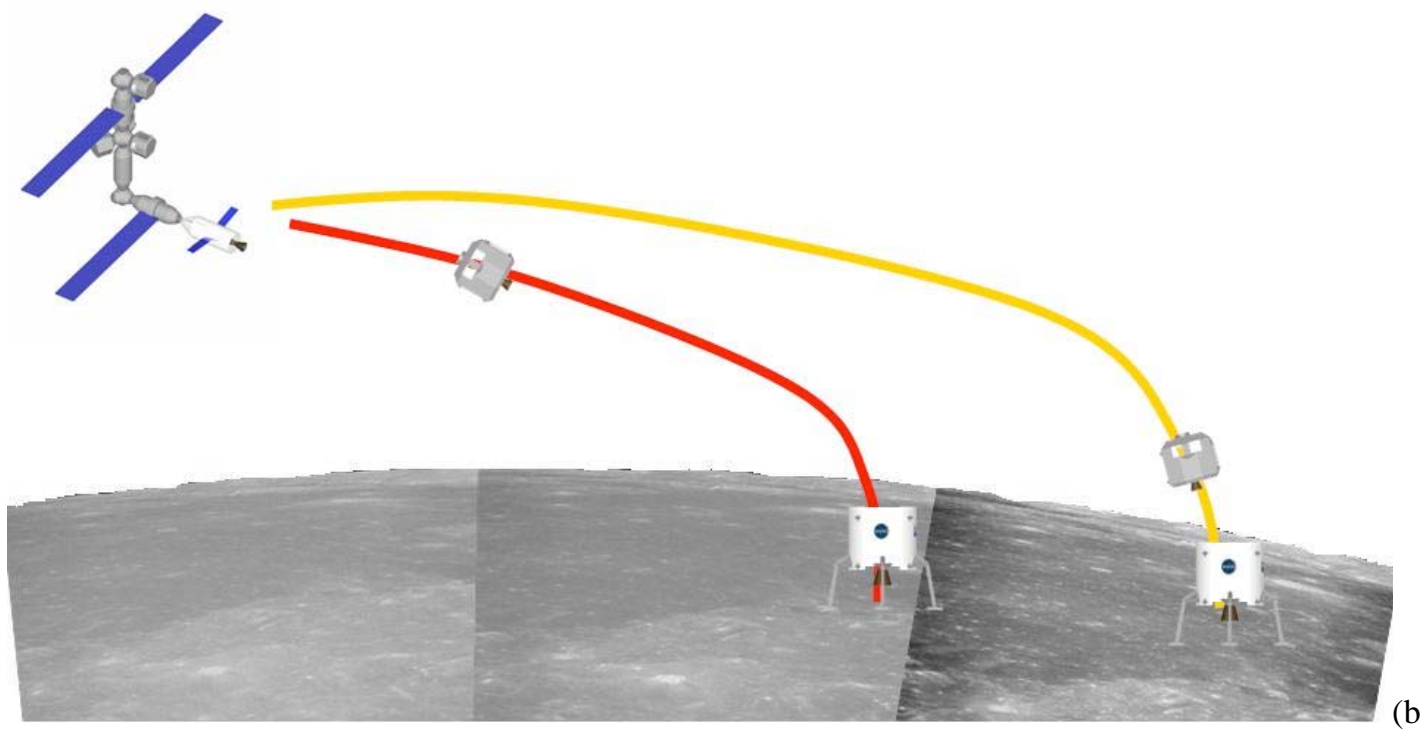

Fig. 6a-b. "Mission Profiles" of Some Notional Lunar Campaigns: (a) Expeditionary Surface Treks and (b) Build-Up Orbital Facilities

\section{Fundamental Questions about Human-Rated Lander Autonomy}

The problem to be studied in this work is easy to describe but difficult to solve:

First, what is the optimum level of vehicle autonomy and intelligence required for a particular human-rated surface lander mission/application, so as to assure acceptable levels of success and safety while at the same time keeping development and implementation costs to a minimum?

Second, what are the specific attributes of an autonomous system implementation essential for a given surface lander mission/application in order to maximize mission success?

Autonomy metrics are defined for this particular mission/application domain that are both quantifiable and practical in terms of their utility. These metrics include level of autonomy, intelligence, and elegance. Autonomy is defined for the purposes of this work as the lander onboard systems' ability to perform certain identified tasks with varying levels of human intervention (whether from the crew and ). Intelligence measures how well these tasks are performed under varying degrees of task and environmental complexity and other associated constraints and conditions. And, elegance is the computational efficiency by which the lander onboard systems' intelligence is 
implemented. Additionally, first order functional relationships are proposed that relate these autonomy metrics to notional human-rated lander characteristics and mission requirements. Finally, the contribution of individual autonomous system technologies (of which a large set of potentially viable technologies will be identified) can be related to high-level programmatic goals, mission cost, risk, and return on investment criteria.

This work, though preliminary in nature, will hopefully serve as a useful tool for exploration system architects in their efforts to assess the optimum strategy for autonomous system technology investment to support future spacecraft development.

\section{Autonomy \& Perception Issues}

As noted in Refs. 12-13 there appears to be a "trust" issue, as well as cost/benefit perception issues (those perceiving something to be more costly or less beneficial than demonstrably it is), for the application of autonomous system technology to spacecraft - particularly human-rated systems. It is also interesting to note the distinction of autonomy in the context of decision-making being made by groundside mission control or onboard the spacecraft (either by the crew or a set of autonomous systems). The distinction is very much highlighted in Ref. 11, wherein two scales/metrics (the "level of automation" and the "level of autonomy") are defined to capture just such groundside versus onboard decision-making issues. These perception issues will need to be dealt with; however, it is clear that incorporation of high-levels of autonomy for crewed spacecraft is inevitable. This position will be argued on the basis of posing the following line of logic (an informal version of reductio ad absurdum argument) in support of the aforesaid conclusion.

(i) Future human spaceflight missions will be much longer in duration and further in deepspace than past efforts. This will pose new challenges for communications with Earth and for supply chain logistics for these future exploration efforts.

(ii) Transporting large quantities of supplies and equipment to lunar and planetary surfaces will require the development of specialized cargo-variants of surface landers; these cargo landers will be fully automated.

(iii) Further, building surface infrastructure for long-term expeditionary campaigns (for semipermanent bases or large temporary encampments) will require the development of a specialized variant of surface lander to transport habitat modules and large infrastructure assemblies; this type of lander will also be fully automated.

(iv) In both the above cases, the timely, efficient, and reliable (i.e. minimum tolerance for failure) transportation of cargo and infrastructure components to lunar and planetary surfaces is equally important to overall mission success and crew wellbeing (when considering the complete mission and not just the in-space phase) as the safety and reliability of the crewed lander operations.

(v) Given the necessity of developing the autonomous system technology for the above highly autonomous lander variants, is it conceivable that mission planners will "discard" that autonomy capability for crewed-variants of the surface landers? In particular, consider the following additional concerns:

(a) What happens if the crew becomes incapacitated (through sickness, or fatigue and debilitation from prolonged in-space transit and/or demanding extended surface operations) in some manner and light-speed delays prohibit safe groundside operation of spacecraft systems? Fully/highly autonomous systems may be the only safety net for the crew under this type of circumstance.

(b) If one restricts oneself to only considering lunar campaigns, versus Mars or other deeps-space mission, such that others might argue that highlevels of autonomy are not required because the heritage of Apollo suggests that such a capability is not needed to be successful, then how does one argue that the lunar campaigns act as a technological/operational steppingstone for future explorations as the Vision for Space Exploration has annunciated? 
(c) Finally, the long-term sustainability of exploration - and ultimately deriving economic benefits from such exploration - will be contingent upon use of advanced robotics and teleoperated systems to act as agents for (their work coordinated both in parallel with and in place of) human beings. All things being equal, a colony of robots has to be cheaper, safer, and, therefore, more sustainable in the long term, than a colony of humans.

(vi) The answer to the question posed above is "no." "No," such highly autonomous system capabilities will not and cannot be restricted ("discarded") in their application to crewed surface landers (and other spacecraft).

\section{System Analysis Methodology}

The basic "system analysis of autonomy" methodology is outlined in this section. The problem to be studied is easy to describe but difficult to solve:

- First, what is the optimum level of vehicle autonomy and intelligence required for a particular surface lander mission/application, so as to assure acceptable levels of success and safety while at the same time keeping development and implementation costs to a minimum?

- Second, what are the specific attributes of an autonomous system implementation essential for a given mission/application and vehicle in order to maximize mission success?

To solve this problem it is first necessary to define metrics to aid in the required system analysis.

\section{A. Concepts and Initial Metrics}

Considerable work has been documented in the literature as to machine intelligence metrics, particularly for terrestrial UAVs, e.g. Refs. 4. 7, and 9; however, only modest work has been dedicated to automation of crewed spacecraft, e.g. Refs. 10-11. Delving briefly into the autonomy versus intelligence debate, autonomy is defined for the purposes of this paper as the ability to independently perform without human intervention actions, tasks, or roles. Intelligence measures how well these actions, tasks or roles are performed under varying degrees of task and environmental complexity and other associated constraints and conditions. And, elegance is the computational efficiency by which the autonomous vehicle intelligence is implemented. Therefore, it is wholly possible that two robotic systems can be at nominally equivalent autonomy levels but exhibit radically different levels of intelligence. For example, one robot (space- or planetary-surface-based or otherwise) could perhaps only perform its tasks in a simple invariant environment, whereas the other robotic system could perform those nominally same tasks in a highly uncertain, unknown, or changing environment. The latter robotic system is clearly more intelligent than the robot that can only successfully operate in the simpler environment, though their autonomy levels may be equivalent. (For example, one can operate with the availability of GPS, the other can operate without the need for GPS.) The more intelligent system requires less infrastructure, and should require less overhead, in order to perform its tasks.

The definitions of intelligence and elegance used in this paper are based upon the work in Ref. 3. In that the Ref. 3 was primarily focused on solely robotic planetary missions it is necessary to make small but significant modifications to the definitions of intelligence and elegance to accommodate crewed (though potentially highly automated) spacecraft. The result is Eqs. (1a-d), which gives the proposed (non-normalized) metrics for vehicle intelligence and elegance (for a given prescribed autonomy level) for the human-rated spacecraft, including the surface lander problem currently being studied:

$$
\text { Intelligence } \equiv \text { Mission Success } \times \frac{\text { Environmental \& Operational Complexity }}{(1+\text { Number of Intelligent Systems }) \times(1+\text { Number of Crew })}
$$


Or, alternatively,

$$
\iota=\frac{S C_{E O}}{\left(1+N_{R}\right)\left(1+N_{\text {crew }}\right)}
$$

Correspondingly,

$$
\text { Elegance } \equiv \frac{\text { Intelligence }}{\text { Autonomous System Complexity } \times(1+\text { Number of Intelligent Systems }) \times(1+\text { Number of Crew })}
$$

Or

$$
\varepsilon=\frac{\iota}{C_{A S}\left(1+N_{R}\right)\left(1+N_{\text {crew }}\right)}
$$

The above expressions for non-normalized intelligence and elegance can now be applied to human-rated highlyautomated spacecraft. In large respect, these changes to accommodate crewed or potentially crewed (versus wholly robotic as originally conceived in Ref. 3) spacecraft are relatively minor. Figure 7 provides a simple illustration of what is exactly implied by this combination of "intelligent systems," robotic technologies, and spacecraft crew.

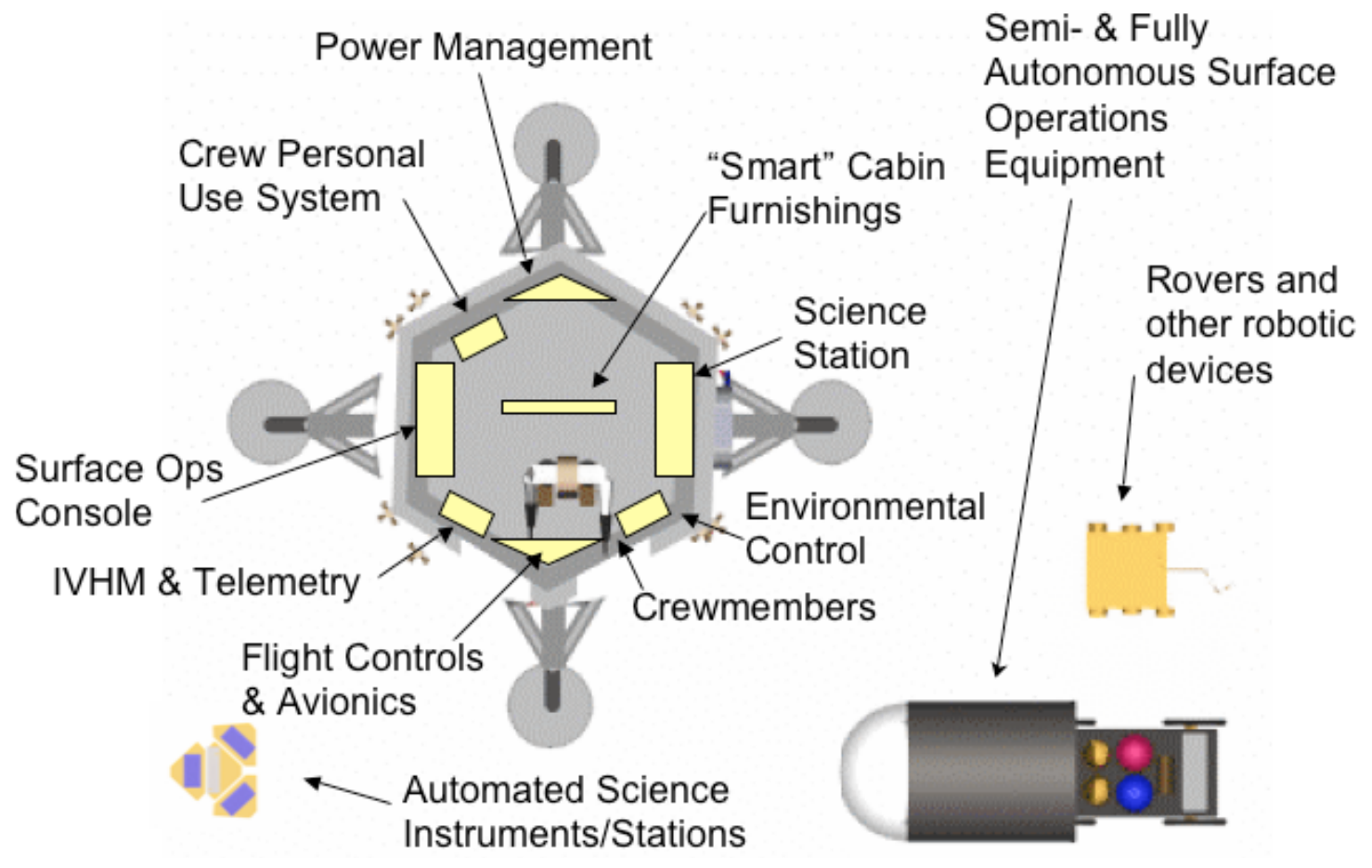

Fig7. Surface landers: a collective system of “intelligent systems," robotic devices, and crew

In introducing the above expressions for the spacecraft intelligence and elegance, two new terms were also introduced: $C_{E O}$, environmental and operational complexity, and, $C_{A S}$, autonomous system complexity. Note that for autonomy levels 3-5, at least, which is the primary focus of the current work, the following holds true: 


\author{
Environmental \& Operational Complexity $\equiv$ \\ System Mobility Degrees of Freedom \\ $\times$ Number of Control Actuators \\ $\times$ Required Control Input Rate \\ $\times$ Number of Sensors \\ $\times$ Degree of Inaccessibility \\ $\times$ Degree of Resistance \\ $\times$ Degree of Interaction \\ $\times$ Inverse of Opportunity Frequency
}

Or, alternatively,

$$
C_{E O}=N_{D O F} N_{C} R_{C} N_{S} D_{I} D_{R} \frac{D_{I N}}{F_{T}}
$$

And

\author{
Autonomous System Complexity $\equiv$ \\ Lines of Software Code \\ $\times$ Number of State Space Variables \\ $\times$ Number of Robotic Behaviors or Programmed Tasks \\ $\times$ Number of Conditio nal (Heuristic) Rules \\ $\times$ Number of Processors \\ $\times$ Size of System Dynamic Memory \\ $\times$ Mean Processor(s) Instruction or Operation Speed
}

Or, rather,

$$
C_{A S}=N_{L} N_{v} N_{B} N_{R u l e^{N}} N_{M} F_{P}
$$

Refer to Table 4 for some of the constituent elements that comprise the definition of the environmental and operational complexity, $C_{E O}$, for surface landers. The exact definition for $C_{E O}$ will vary from application domain to application domain, though there are some common elements in general with the various autonomous system applications. Eqs. 2c-d have, therefore, also been slightly recast and revised from the Ref. 3 definitions/expressions to reflect the shift in application focus from fully autonomous planetary robotic systems (particularly that of planetary aerial vehicles, a.k.a "aerial explorers," such as Mars airplanes) to crewed spacecraft embodying various types of autonomous systems. 
Table 4 -- Defining Environmental and Operation Complexity

\begin{tabular}{|c|c|c|c|c|}
\hline $\begin{array}{c}\text { Types of } \\
\text { Applications or } \\
\text { Systems }\end{array}$ & $\begin{array}{c}\text { Factors Affecting } \\
\text { "Degree of } \\
\text { Inaccessibility" }\end{array}$ & $\begin{array}{c}\text { Factors Affecting } \\
\text { "Degree of } \\
\text { Resistance" }\end{array}$ & $\begin{array}{c}\text { Factors Affecting } \\
\text { "Degree of } \\
\text { Interaction" }\end{array}$ & $\begin{array}{c}\text { Factors Affecting } \\
\text { "Opportunity" } \\
\text { Frequency }\end{array}$ \\
\hline Surface lander vehicle & $\begin{array}{l}\text {-- Terrain ruggedness at } \\
\text { landing site } \\
\text {-- Distance from "safe" } \\
\text { landing site to field sites or } \\
\text { encampments } \\
\text {-- Target landing site } \\
\text { coordinates might be } \\
\text { difficult to achieve from an } \\
\text { orbital mechanics } \\
\text { perspective }\end{array}$ & $\begin{array}{l}\text {-- Landing and excursion } \\
\text { stays at sites under extreme } \\
\text { diurnal or seasonal } \\
\text { conditions (e.g. lunar } \\
\text { "night" and "day") } \\
\text {-- Environmental conditions } \\
\text { such as wind, dust, } \\
\text { electrostatic charge for } \\
\text { planetary bodies with } \\
\text { significant atmospheres (i.e. } \\
\text { Mars) } \\
\text {-- Environmental conditions } \\
\text { such as dust, radiation, etc. }\end{array}$ & $\begin{array}{l}\text {-- Number of external } \\
\text { science instruments and } \\
\text { robotic devices directly } \\
\text { operated from lander } \\
\text { science station } \\
\text {-- Number of surface } \\
\text { operations hardware } \\
\text { operated remotely from } \\
\text { lander } \\
\text {-- Networking with other } \\
\text { pre-existing surface, } \\
\text { orbital, and earth-side } \\
\text { assets }\end{array}$ & $\begin{array}{l}\text {-- Density of surface } \\
\text { features of geologic (or } \\
\text { astrobiology) interest near } \\
\text { landing site or } \\
\text { encampment } \\
\text {-- Density, accessibility, } \\
\text { and utility of in-situ } \\
\text { resources } \\
\text {-- Availability of } \\
\text { acceptable sites from an } \\
\text { infrastructure perspective } \\
\text { (level surface, good soil } \\
\text { characteristics, etc.) }\end{array}$ \\
\hline $\begin{array}{l}\text { Rovers and other } \\
\text { robotic surface } \\
\text { operation hardware }\end{array}$ & $\begin{array}{l}\text {-- Terrain ruggedness } \\
\text { impeding access of } \\
\text { wheeled/tracked platform } \\
\text {-- Availability of solar } \\
\text { flux, temperature } \\
\text { conditions } \\
\text {-- Limitations of } \\
\text { communication and data } \\
\text { relay } \\
\text {... }\end{array}$ & $\begin{array}{l}\text {-- Surface traction (or lack } \\
\text { thereof) } \\
\text {-- Grade of terrain slope } \\
\text { and/or elevation } \\
\text {-- Amount and type of } \\
\text { surface dust/soil as to } \\
\text { potentially gumming up } \\
\text { mechanisms or covering } \\
\text { solar arrays } \\
\text {... }\end{array}$ & $\begin{array}{l}\text {-- Required level of robot- } \\
\text { to-robot and intelligent- } \\
\text { system to intelligent } \\
\text { coordination (from a peer } \\
\text { or equal-to-equal } \\
\text { perspective or a } \\
\text { leader/subordinate } \\
\text { relationship) required to } \\
\text { perform primary tasks } \\
\text {... }\end{array}$ & $\begin{array}{l}\text {-- Anticipated distribution } \\
\text { of notable and accessible } \\
\text { rock formations } \\
\text {-- Anticipated depth of } \\
\text { subsurface ice and other } \\
\text { soil constituents for } \\
\text { drilling } \\
\text {-- Anticipated or } \\
\text { hypothesized presence of } \\
\text { signs of ancient water }\end{array}$ \\
\hline $\begin{array}{l}\text { Planetary aerial } \\
\text { vehicles, a.k.a. aerial } \\
\text { explorers (Ref. 3) }\end{array}$ & $\begin{array}{l}\text {-- Terrain ruggedness } \\
\text { obscuring surface features } \\
\text { of interest } \\
\text {-- Atmospheric density at } \\
\text { altitude of interest } \\
\text { Limitations in data relay } \\
\ldots\end{array}$ & $\begin{array}{l}\text {-- Atmospheric turbulence } \\
\text {-- Wake/winds off of large } \\
\text { geologic formations } \\
\text { buffeting vehicle } \\
\text {-- Icing or contamination of } \\
\text { control surfaces } \\
\ldots\end{array}$ & $\begin{array}{l}\text {-- Number and persistence } \\
\text { of air-deployed } \\
\text { probes/devices } \\
\text {-- Number of other pre- } \\
\text { existing spacecraft assets } \\
\text { interacted with } \\
\ldots\end{array}$ & $\begin{array}{l}\text {-- Pre-mission anticipated } \\
\text { survey area density of } \\
\text { discrete targets of } \\
\text { scientific interest } \\
\text {-- Ratio of estimated } \\
\text { vehicle range (squared) to } \\
\text { ideal survey area } \\
\text {... }\end{array}$ \\
\hline $\begin{array}{l}\text { Terrestrial HALE } \\
\text { UAV (Ref. 4) }\end{array}$ & $\begin{array}{l}\text {-- Amount of solar flux } \\
\text { available (for solar- } \\
\text { powered vehicles) for a } \\
\text { given time of year and } \\
\text { latitude } \\
\text {-- Optimal altitude (e.g. } \\
\text { cruise at } 60 \mathrm{Kft} \text { might be } \\
\text { achievable technology- } \\
\text { wise but not } 100 \mathrm{Kft} \text { ) }\end{array}$ & $\begin{array}{l}\text {-- Cross-winds during take- } \\
\text { off/landing and/or transit to } \\
\text { operating altitude } \\
\text {-- For military applications, } \\
\text { could include effectiveness } \\
\text { of surface to air defenses of } \\
\text { opponent } \\
\ldots\end{array}$ & $\begin{array}{l}\text {-- Total number of aerial } \\
\text { assets required to perform } \\
\text { the mission } \\
\text {-- Number of ground } \\
\text { control stations and } \\
\text { operators } \\
\text {-- Number of satellite } \\
\text { assets for adequate data } \\
\text { bandwidth }\end{array}$ & $\begin{array}{l}\text {-- In search and rescue } \\
\text { applications (SAR), the } \\
\text { total number of missing } \\
\text { personnel } \\
\text {-- E.g. SAR, again, the } \\
\text { uncertainty in extent and } \\
\text { location of survey area } \\
\text {... }\end{array}$ \\
\hline
\end{tabular}

In deriving the autonomous system complexity metric, the "collective" system complexity should be used to estimate $C_{A S}$. (The term "collective" being used in the sense of including all of the multiple automated/autonomous systems onboard, or integrated with, the surface lander - including all those systems noted in Fig. 7 -- excluding the crewmembers.) In this regard a surface lander can be thought of as collective on interdependent automated/autonomous systems both internal and external to the lander itself; such a whole collective whole of systems contribute to the success - and risk and cost - of the complete mission and not just the in-flight descent and ascent operation of the spacecraft.

As noted in the above definitions of intelligence and elegance, mission success is an intrinsic parameter to those definitions. In addition to mission success, from a systems analysis perspective, it also important to assess mission return on investment. Mission return on investment (MROI) - versus ROI in the macroeconomic-sense - can be expressed as

$$
M R O I=\frac{\text { Mission } \text { Success }}{\text { Risk } \cdot \text { Cost }}
$$


Table 5 notes a number of different measures/metrics for estimating/tracking mission success that can be defined. Each type of mission has its own unique mission success metric (though there are certain common constituent elements). Assessing overall mission success needs to be established through a combination of flight test and mission simulation. This will be discussed subsequently in the context of autonomous system technology validation. Some of the notional vehicle systems associated with the Table 5 missions are shown in Fig. 8.

Table 5 -- Mission Success Metrics for Various Notional Missions/Campaigns

\begin{tabular}{|c|c|}
\hline Mission & Mission Success Metric \\
\hline $\begin{array}{l}\text { Crewed Surface Lander } \\
\text {--Short Stay Excursions } \\
\text {-- Extended Stay }\end{array}$ & $S \propto N_{c r e w} T \Delta v$ \\
\hline $\begin{array}{l}\text { Automated Cargo Deployment } \\
\text {-- Pallet, Habitat, etc. }\end{array}$ & $S \propto m_{c} \chi \varphi T \Delta v$ \\
\hline $\begin{array}{l}\text { Science "Investigations" } \\
\text {-- As a part of short and extended } \\
\text { stay excursions \& occupancy of } \\
\text { surface bases or orbital facilities }\end{array}$ & $\begin{array}{l}S \propto \text { Information Gathered }= \\
\quad \text { Number of sensors } \times \text { Measure of spatiotemporal dispersal of sensors } \\
\quad \times \text { Mean sophistication of sensors } \times \text { Number of different types of sensors } \\
\quad \times \text { Ability to interprete or adapt given past results } \times \text { Ability to verify results } \\
\quad \times \text { Ability to cross correlate independent measurements }\end{array}$ \\
\hline \multicolumn{2}{|c|}{ 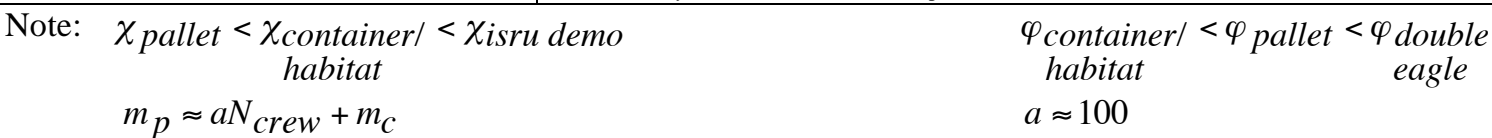 } \\
\hline
\end{tabular}
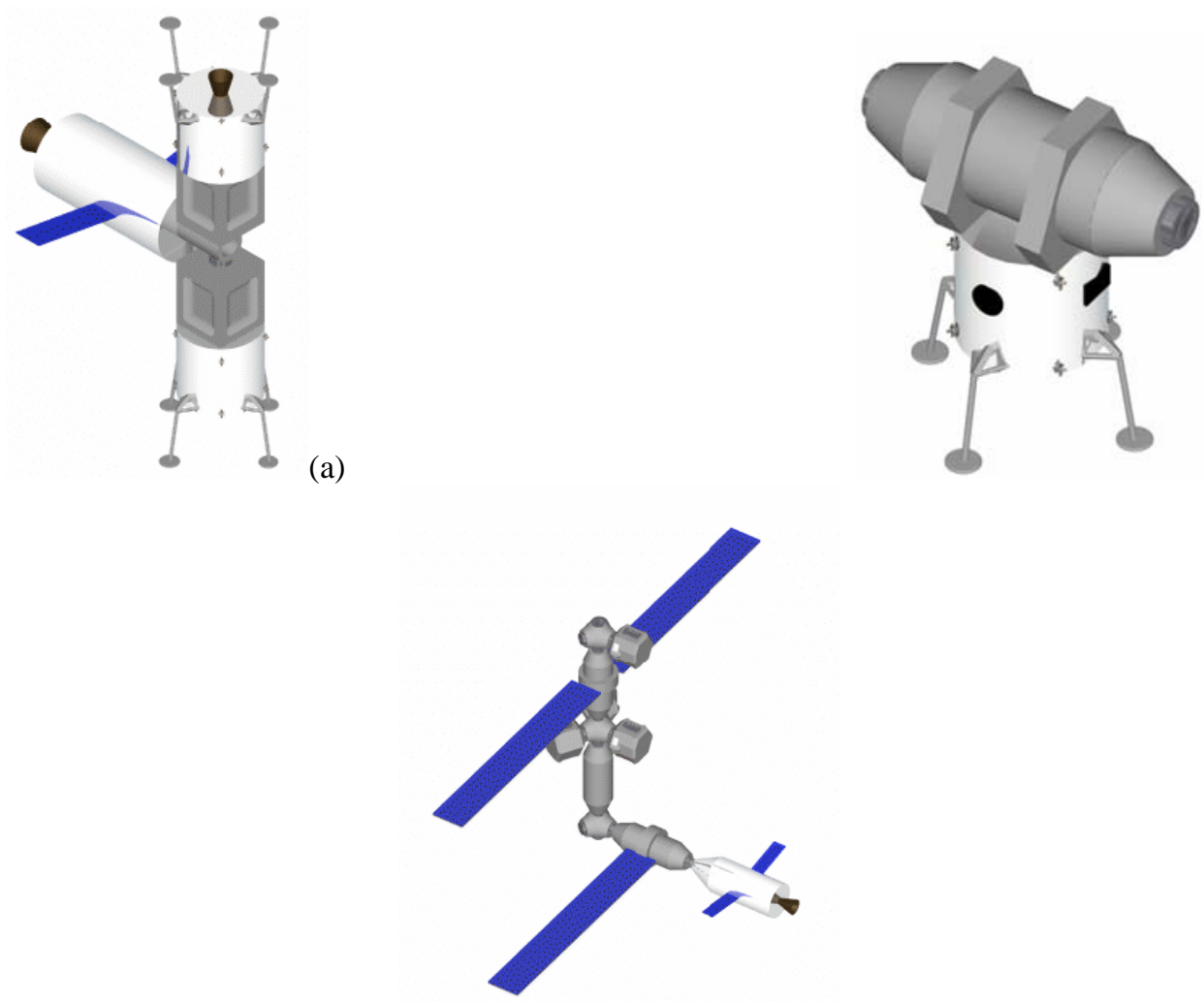

(b)

(c)

Fig. 8. (a) "Double Eagle" Cargo Pallet Delivery in Support of Expeditionary Trek, (b) "Habitat" Cargo Variant, and (c) Orbital Facility 
Note that there are no upper bounds on the above definitions of the mission success, intelligence and elegance metrics. Their maximum values are dependent upon a given set of vehicle, environmental, and mission characteristics -- which, in turn, are subject to refinement as vehicle designs are matured, mission concept of operations (CONOPS) are detailed, and system characteristics are predicted with improved fidelity analysis/simulation tools and/or measured in flight. Though these autonomy metrics can and should be defined by using the above detailed formulae, a simpler approach should be used when system analysis of vehicle/mission concepts is to be performed. Therefore "normalized versions of system intelligence and elegance, $\iota^{*}$ and $\varepsilon^{*}$, must be defined where the normalized values fall within the ranges $0 \leq \iota^{*} \leq 10$ and $0 \leq \varepsilon^{*} \leq 10$. That is, it is posited that there are some notional normalization factors such that $\iota^{*} \equiv \iota / \iota_{\text {Constant Factor }}$ and $\varepsilon^{*} \equiv \varepsilon / \varepsilon_{\text {Constant Factor }}$ wherein the above range of values holds true for all realizable exploration surface lander missions. In practice, neither quantitative estimates of $\boldsymbol{\iota}$ and $\varepsilon$, or definition of actual values of $\boldsymbol{\iota}_{\text {Constant Factor }}$ and $\varepsilon_{\text {Constant Factor }}$ need be made in order to gain some advantage from the concept of using normalized measures for these key parameters. The proposed "normalization" is a pragmatic technique that allows engineering judgment to be used in the early stages of the system analysis process, in place of making detailed but difficult estimates of vehicle intelligence and elegance using Eqs. 1-4. It is anticipated that the intelligence and elegance metrics will occasionally need to be re-normalized with improved mission simulation and autonomous system development results. Correspondingly, the degrees of inaccessibility, $\mathrm{D}_{\mathrm{I}}$, degrees of resistance, $\mathrm{D}_{\mathrm{R}}$. and degrees of interaction, $\mathrm{D}_{\mathrm{IN}}$, can also be "normalized" to range between the values of 0 to 10 and engineering judgment used in place of detailed analysis and mission simulation to define these parameters.

\section{B. Assessing First-Order Cost and Risk}

In the most global sense, mission success, risk, and costs are functions of not only the vehicle LOA, but also the vehicle's intelligence, $\iota$, and elegance, $\varepsilon$, at a given LOA. Mission success, as noted earlier, can only be assessed in terms of flight test and simulation. On the other hand, first-order parametric expressions can be posited for the functionality of risk and cost with respect to a vehicle's intelligence and the elegance of its autonomous system implementation. Specifically, for the purposes of this exercise, it is conjectured that the functional forms for the risk and cost metrics are, respectively, as follows:

$$
\begin{gathered}
\text { Risk } \approx x\left(T, N_{\text {crew }}, M T B F, \ldots\right) f\left(\iota^{*}, \varepsilon^{*}\right) \\
\text { Cost } \approx y\left(T, N_{\text {cew }}, M T B F, \ldots\right) g\left(\iota^{*},{ }^{*}\right) h(\aleph)
\end{gathered}
$$

Where the dependence of vehicle/mission risk and cost on total system level of autonomy, intelligence, and elegance is given by the general functions: $h(\aleph), f\left(\iota^{*}, \varepsilon^{*}\right)$, and $g\left(\iota^{*}, \varepsilon^{*}\right)$. The "non-autonomy-related vehicle, payload, or service interruption risks are encapsulated in the functions $x\left(T, N_{\text {crew }}, M T B F, \ldots\right)$ and $y\left(T, N_{\text {cew }}, M T B F, \ldots\right)$. These functions must be semi-empirically derived from heritage spacecraft data and projected risk and cost estimates. The derivation of these functions is beyond the scope of this paper.

Possible functions for a simple model of the dependence of vehicle/mission cost and risk on total system level of autonomy, intelligence, and elegance is given by the expressions

$$
f\left(\iota^{*}, \varepsilon\right) \approx \frac{a_{2}\left(\varepsilon^{*}\right)^{-n_{2}}}{a_{1}+\left(\iota^{*}\right)^{n_{1}}}+a_{3}\left(\iota^{*}\right)^{n_{3}}
$$




$$
\begin{gathered}
g\left(\iota^{*}, \varepsilon^{*}\right) \approx c_{1}\left(\iota^{*}\right)^{m_{1}}\left(\varepsilon^{*}\right)^{-m_{2}} \\
h(\boldsymbol{\aleph}) \approx(1+\aleph)^{m_{0}}
\end{gathered}
$$

In effect, Eq. 4a-e can be considered a generalization of the early work presented for aerial explorers and planetary robotic systems, Ref. 3, and high-altitude long endurance UAVs, Ref. 4.

\section{Relationship between Mission Requirements and Autonomy Requirements}

Drawing upon the Table 2 mission descriptions and the Table 5 mission success metrics, Table 6 summarizes an assessment, using engineering judgment at this point of the analysis, as to key operational/environmental parameters that will be used shortly to postulate functional relationships between these parameters and metrics for surface lander intelligence and elegance. Further refinement of the Table 6 data as regards the interdependence of mission versus autonomy requirements can be established through appropriate polling of subject matter experts (SME's). Subsequently, as the system designs mature, design data and test and evaluation results to help further refine the autonomy requirements. However, for initial system analysis trend studies the Table 6 results should provide valuable insight into the relative necessity for autonomous system technologies. $D_{I}^{*}, D_{R}^{*}$, and $D_{I N}^{*}$ denote respectively the normalized degrees of inaccessibility, resistance, and interaction.

\begin{tabular}{|c|c|c|c|c|c|c|c|}
\hline $\begin{array}{l}\text { Notional Lander Missions or } \\
\text { Campaigns }\end{array}$ & $\begin{array}{c}\text { Number of } \\
\text { Crew } \\
\text { Members }\end{array}$ & $\begin{array}{c}\text { Mission } \\
\text { Duration, T } \\
\text { (Days) }\end{array}$ & $\begin{array}{l}D_{I}^{*} \\
(\mathbf{1 - 1 0})\end{array}$ & $\begin{array}{l}D_{R}^{*} \\
(\mathbf{1 - 1 0})\end{array}$ & $\begin{array}{l}D_{I N}^{*} \\
(\mathbf{1 - 1 0})\end{array}$ & $\stackrel{(\aleph}{(1-10)}$ & $\stackrel{\iota *}{\iota}$ \\
\hline Short Stay Excursions & 4 & 10 & 1 & 1 & 1 & 1 & 3 \\
\hline Extended Stay & 4 & 40 & 3 & 3 & 3 & 5 & 6 \\
\hline $\begin{array}{l}\text { Automated Cargo Deployment } \\
\text { (Pallet) }\end{array}$ & 0 & 3 & 1 & 1 & 1 & 2 & 3 \\
\hline $\begin{array}{l}\text { Automated Cargo Deployment } \\
\text { (Habitat) }\end{array}$ & 0 & 3 & 1 & 5 & 1 & 2 & 4 \\
\hline $\begin{array}{l}\text { "Double Eagle" Lander } \\
\text { Deployment }\end{array}$ & 0 & 3 & 1 & 1 & 1 & 2 & 3 \\
\hline $\begin{array}{l}\text { Automated Cargo Deployment } \\
\text { (ISRU/Utility) }\end{array}$ & 0 & 3 & 1 & 3 & 3 & 2 & 5 \\
\hline Orbital Facility Build-Up & 4 & 60 & 2 & 1 & 3 & 2 & 6 \\
\hline Great Treks & 4 & $>40$ & 5 & 5 & 5 & 2 & 7 \\
\hline $\begin{array}{l}\text { Test Drive (evaluation of future } \\
\text { exploration systems) }\end{array}$ & 4 & 40 & 8 & 8 & 10 & 9 & 9 \\
\hline Lunar Observatories & 4 & $>1095$ & 5 & 5 & 7 & 4 & 7 \\
\hline In-Situ Resource Demonstrations & 0 & $>120$ & 5 & 7 & 7 & 4 & 8 \\
\hline $\begin{array}{l}\text { Robotic Outposts \& Virtual } \\
\text { Presence }\end{array}$ & 0 & $>1095$ & 5 & 6 & 10 & 7 & 8 \\
\hline
\end{tabular}

Table 6 -- Functional Relationship Assessment 
As can be expected, the Table 6 values are only approximate descriptions of a broad range of possible mission types. Resulting functional relationships have been derived on the basis of functional analysis using the Table 6 "data" - which in turn was derived using engineering judgment. Note that an additional parametric influence for total mission $\Delta v$, "Delta- $\mathrm{V}$," and the influence of crew size, $N_{c r e w}$, is included in the normalized intelligence expression. Including the total mission $\Delta v$ provides a means of accounting for the increasing complexity and arguably the increasing importance of system reliability (including that of the autonomous system technologies) of deep space planetary (versus lunar) missions. The crew size also influences the required intelligence of the spacecraft. With increasing crew size more tasks could theoretically be performed manually, if necessary. On the other hand, more crewmembers likely dictate greater sophistication in environmental controls and crew amenities (including, of course, the intrinsic autonomous system technologies built into such systems). Refer to the following:

$$
\iota^{*}=f\left(N_{\text {crew }}, T, \Delta v, D_{I}, D_{R}, D_{I N}, \aleph\right)
$$

Figure 9 qualitatively illustrates (in a "development arc" type chart) the nominal functionality of the normalized intelligence metric with respect to one of the key mission parameters identified in Table 6 and Eq. 5, i.e. $T$, mission duration.

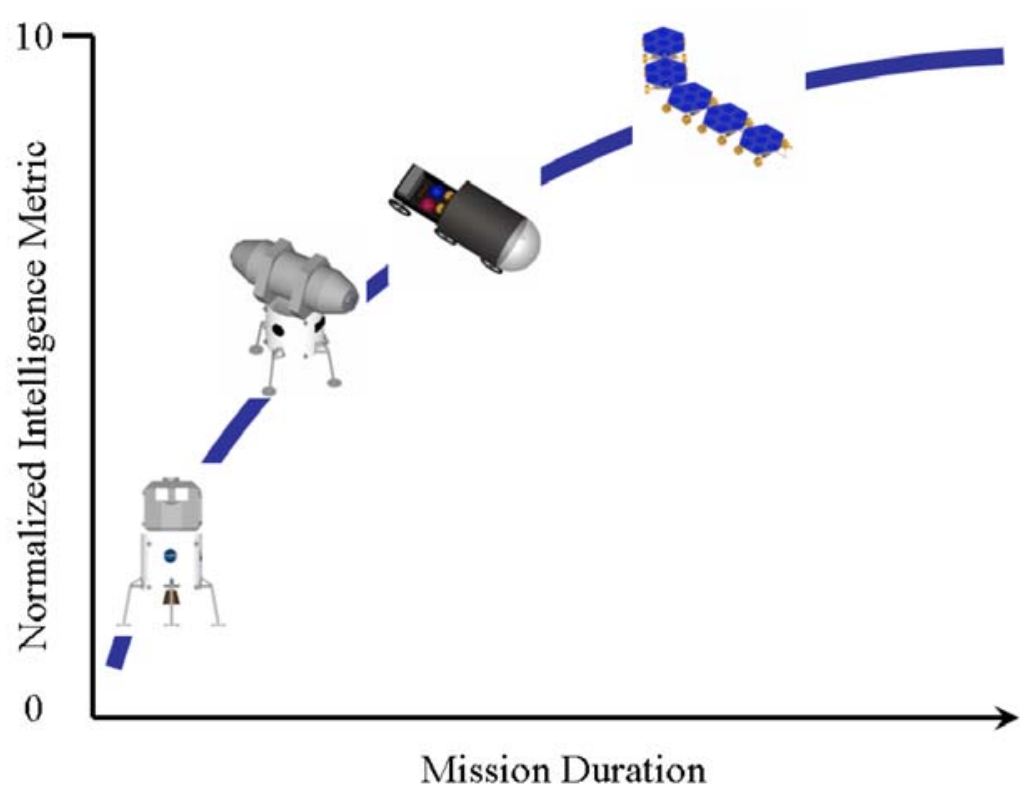

Fig. 9. "Development Arc" Chart for Mission Capabilities (i.e. Mission Duration) as a Function of Achieving a Target Normalized Intelligence Metric

It is postulated that the relative parametric influence of the mission parameters on spacecraft intelligence can be given nominally by the relative contribution breakout seen in Fig. 10. 


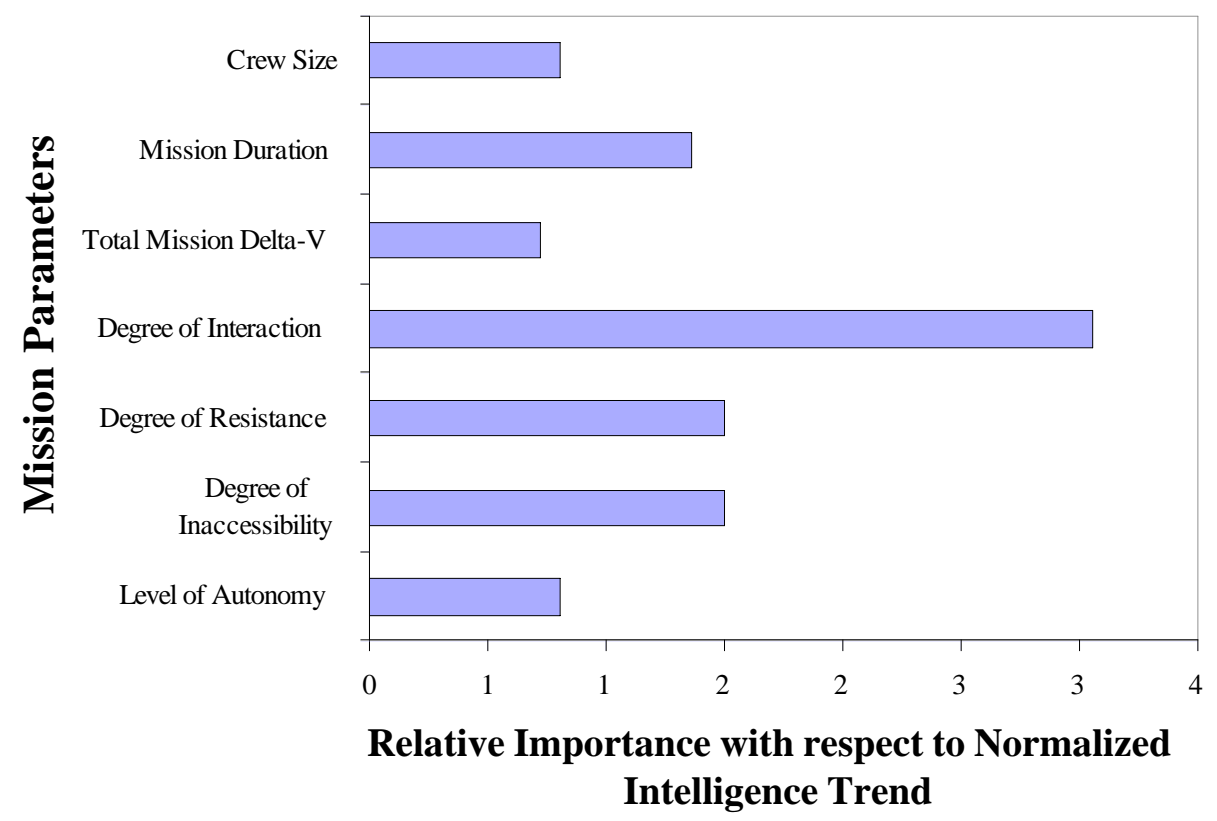

Fig. 10. Postulated Relative Mission Parameter Contributions to Normalized Intelligence Metric

Going one step further, it is conjectured that the functionality of Eq. 5 can be expressed by the simple model

$$
\begin{array}{r}
\iota^{*} \approx \frac{a_{0}}{\left(1+N_{\text {crew }} e^{-m_{0} N_{\text {crew }}}\right)}+a_{1}(1+u(\aleph-2)+u(\aleph-5)+u(\aleph-9))+a_{2} D_{I}^{*}+a_{3} D_{R}^{*} \\
+a_{4}\left(1-e^{-m_{1} D_{I N}^{*}}\right)+a_{5} e^{-m_{2} / \Delta v}+a_{6} e^{-m_{3} / T}
\end{array}
$$

Where the following constant values are suggested (so at to arrive at a nominal, though not exact, agreement with the Table 6 data, i.e. a non-rigorous "curve-fitting" of the trend data being attempted): $\mathrm{a}_{0}=0.8, \mathrm{a}_{1}=0.2, \mathrm{a}_{2}=0.15, \mathrm{a}_{3}$ $=0.15, \mathrm{a}_{4}=3.0, \mathrm{a}_{5}=0.8$, and $\mathrm{a}_{6}=1.5 ; \mathrm{m}_{0}=0.5, \mathrm{~m}_{1}=0.5, \mathrm{~m}_{2}=1$, and $\mathrm{m}_{3}=10$. Figure 11a-g illustrates the incremental contribution of each parameter to the normalized intelligence metric. 

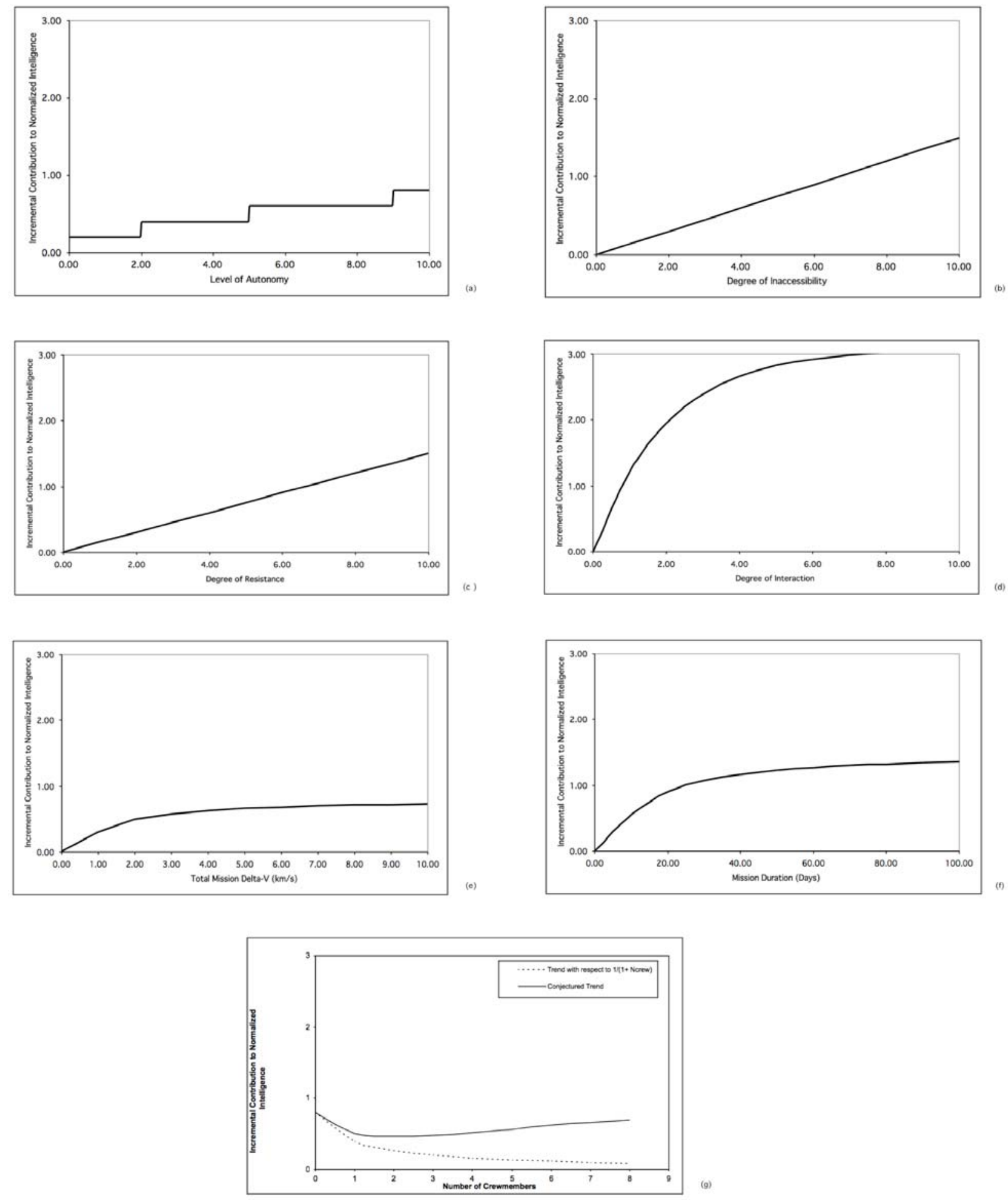

Figure 11a-g. Incremental Vehicle Normalized Intelligence Contribution from Key Mission Parameters: (a) LOA, (b) $D_{\mathrm{I}}$, (c) $\mathrm{D}_{\mathrm{R}}$, (d) $\mathrm{D}_{\mathrm{IN}}$, (e) total mission "Delta-V," (f) mission duration, and (g) crew size 


\section{Individual Autonomous System Technologies \& Achieving Autonomy Metrics \& Goals}

Relating the development progress and contribution of individual technologies, represented by the $j^{\text {th }}$ array element $\mathbf{B}_{j}^{*}$, to the overall intelligence metric for autonomous vehicles is performed as follows

$$
\mathbf{B}_{j}^{*}=\frac{\mathbf{W}_{j}^{*} \mathbf{B}_{j}+W_{0}^{*} \mathbf{I}_{j}^{*} S}{\mathbf{W}_{j}^{*}+W_{0}^{*}} \quad \text { for } \mathrm{j} \geq 1
$$

Where $\mathrm{S}$ is a normalized $(\mathrm{S} \leq 1)$ "mission success" metric derived from mission simulations incorporating the individual autonomous system technologies in specified set of vehicle/mission scenarios. Note that $\mathbf{W}_{0}^{*}$ and $\mathbf{W}_{j}^{*}$ comprise a set of weighting factor metric for relative weighting given to the two types of technology assessments embodied in Eq. 7. The weight $\mathbf{W}_{0}^{*}$ is given to the "objective" simulation-derived mission success technology assessment. The weight $\mathbf{W}_{j}^{*}$ is given to the technologist's "self-assessment" of the normalized technology readiness level (TRL) of the jth autonomous system technology implemented in the mission simulation, $\mathbf{B}_{j}$, or as otherwise denoted by

$$
B \equiv\left[\begin{array}{c}
\text { TRL of the } 1 \text { st Technology divided by "9" } \\
\ldots \\
\text { TRL of the jth Technology divided by "9" } \\
\ldots
\end{array}\right]
$$

Note by definition that $W_{0}^{*}+\mathbf{W}_{j}^{*}=2$ must hold true for all technologies, i.e. all values of $\mathbf{j}$. The weights $\mathbf{W}_{j}^{*}$ are specified as follows, relying on the matrix $\mathbf{Q}$, which in turn is derived from the QFD-inspired tabular matrix shown in Fig. 12.

$$
\mathbf{W}_{j}^{*}=a \mathbf{I}_{j}^{*} \quad \text { and } \quad \mathbf{I}_{j}^{*}=u\left(10 \frac{\mathbf{W}_{j}}{W_{F}}+\iota^{*}-9\right)
$$

Where

$$
W_{F}=\max (\mathbf{W}) \quad \text { and } \quad \mathbf{W}_{j}=\sum_{i} \mathbf{Q}_{i, j}
$$

The constant a, Eq. 9a, is arbitrarily assigned to reflect the relative weight of $\mathbf{W}_{j}^{*}$ with respect to $\mathbf{W}_{0}^{*}$; a=1.0 is suggested. The array $\mathbf{W}$ can be thought of as denoting the relative importance of each individual technology, based upon the $\mathbf{Q}$ matrix input, as to contributing the overall goals of the project. This will be discussed further in the analysis and results section. Note that during the course of flight tests and/or mission simulations (embodying the autonomous system implementation), if an individual technology is not implemented then the "TRL" value of that technology is set to zero (irrespective of its previously demonstrated, but not implemented in the current simulation or flight test). 


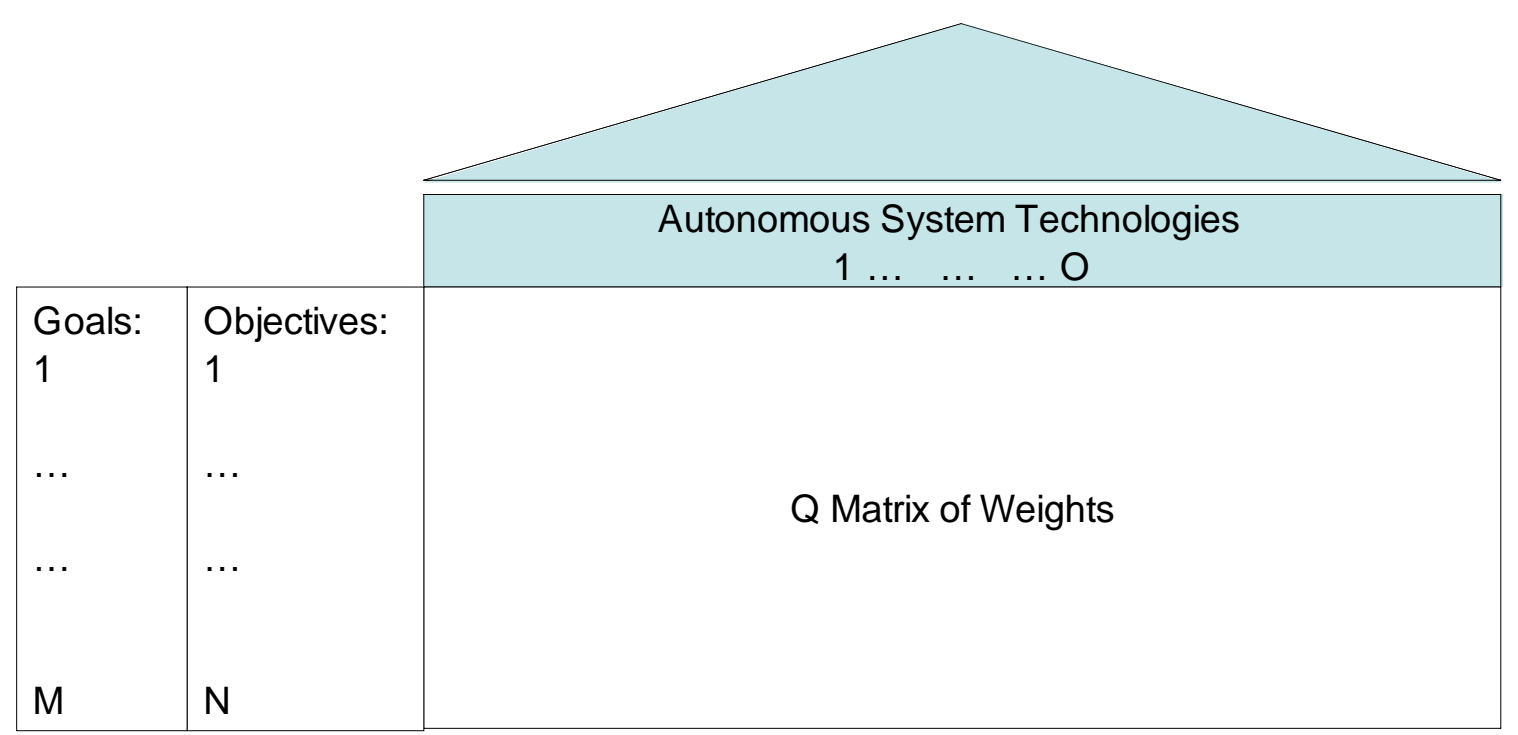

Figure 12. General format of QFD-Inspired Tabular Matrix

\section{Technology Portfolio}

Finally, the progress towards developing individual autonomous system technologies needs to be tracked against progress towards overall programmatic goals/objectives (in so far as affected by those same autonomous system technologies, and not other "extraneous" vehicle technologies). This is accomplished in the proposed analysis by the following relationship for "fractional anticipated contribution to goal" array, $\mathbf{C}_{i}^{*}$.

$$
\mathbf{C}_{i}^{*}=\mathbf{C}_{i} / \sum_{j} \mathbf{Q}_{i, j}
$$

Where

$$
\mathbf{C}=\mathbf{Q B}^{*}
$$

Note that by definition, for a given i'th row of the matrix $\mathbf{Q}$, the following holds true

$\sum_{j} \mathbf{Q}_{i, j} \leq 1$

Note that the initial weighting factors, $\mathbf{Q}_{\mathrm{i}, \mathrm{j}}$, used in the Fig. 12 QFD-inspired matrix can be determined as per Eq. 13. This initial weighting factor scheme can either assume that all contributing autonomous system technologies uniformly/equally contribute to the i'th Goal or. Alternatively, the weighs can be nominally partitioned between enabling $(A=1)$ and contributing technologies $(A=0.25)$.

$$
\mathbf{Q}_{i, j}=\frac{A}{\text { Number of Contributing Autonomous System Technologies, including j' th technology, to ith Goal }}
$$


Subsequent iterations on the Fig. 12 weighting factors can be adjusted to reflect sensitivity analysis results and/or mission simulations that show that autonomous system technologies do not uniformly contribute to the goals. Additionally, the weighting factors can also reflect resource/funding issues that may not fully stem from engineering considerations alone (i.e. not all promising technologies may be funded at the required levels, or funded at all, to achieve the anticipated contributions to the technology goals).

Figure 13 reveals a little more closely some of the interchangeability of information between the QFD-like Qmatrix and the GOTChA process. Aspects of this limited interchangeability of information has great utility - first, in terms of visualization/presentation of Q-matrix results in the, perhaps more familiar, GOTChA format and, second, the GOTChA process can be used as an efficient means of data entry for the Q-matrix. In fact this was the process by which the initial Q-matrix was populated in the Ref. 4 work.
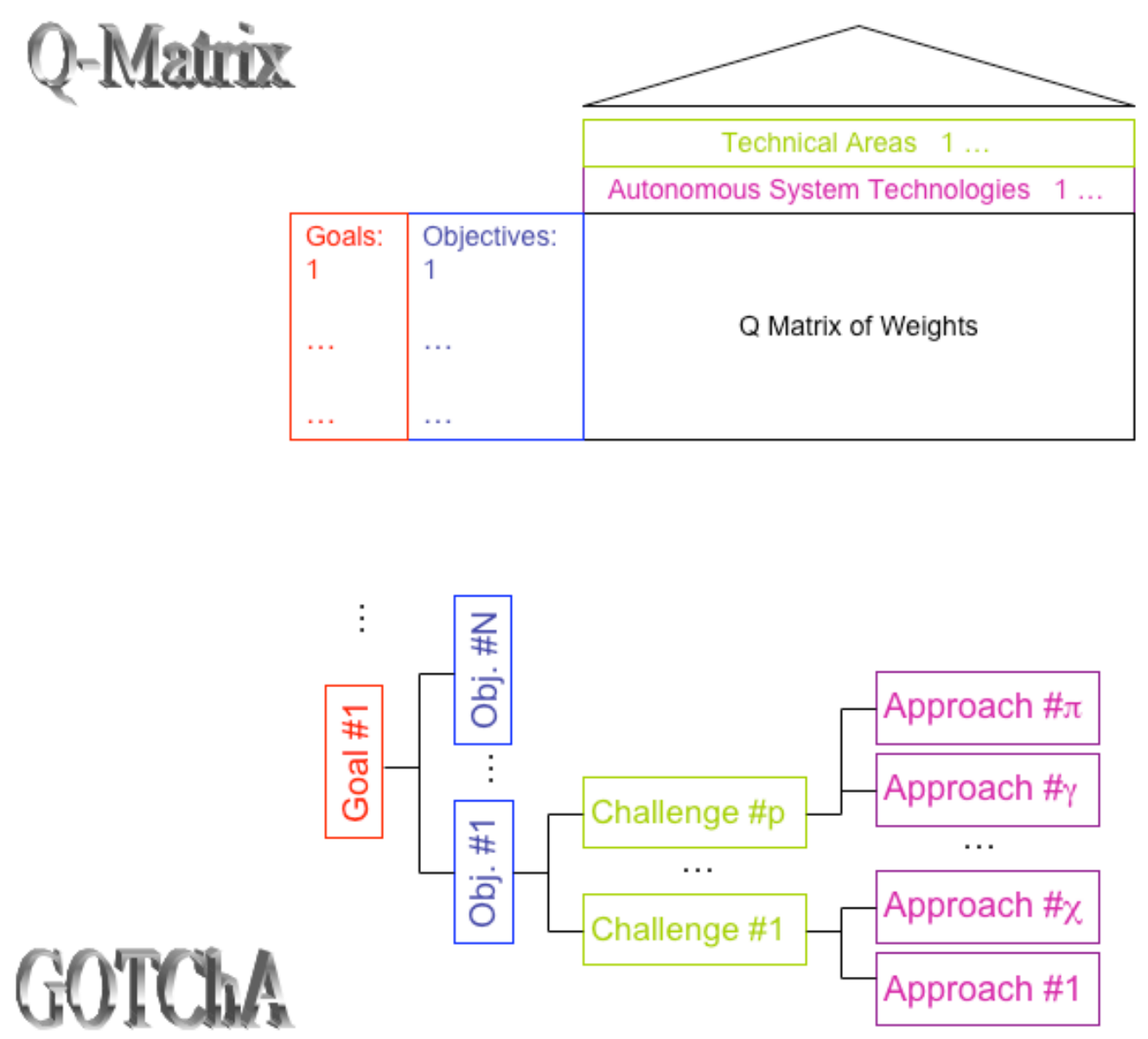

Fig. 13. Information Exchange between the Q-matrix and the GOTChA Methodologies (highlighted by color coding)

It is appropriate to examine these notional vehicle/mission autonomous system capabilities in the context of a matrix inspired by Quality Function Deployment (QFD) "house of quality" matrix representation (see Ref. 14) refer to Fig. 14. The contents of this matrix naturally flow from goals, objectives, technical challenges, and approaches as derived by the well-known "GOTChA" process, refer, for example, to Ref. 15. Note that the matrix columns represent the definition of a detailed technology capability set -- as affected (and only affected) by autonomous system technology. 